\title{
Correction to: Trade liberalization and the wage gap: the role of vertical linkages and fixed costs
}

\section{Francesco Di Comite $^{1}$ (D) Antonella Nocco ${ }^{2} \cdot$ Gianluca Orefice $^{3}$}

\section{Correction to: $\operatorname{Rev}$ World Econ \\ DOI 10.1007/s10290-017-0293-1}

In the original publication of the article, the sign " $<$ " has been converted into latex code "lt0" and the sign " $>$ " has been missed in one of the equations. The correct equation is given below:

$$
\frac{\partial W^{\zeta}}{\partial p_{s}^{\zeta}}<0 ; \quad \frac{\partial W^{\zeta}}{\partial w^{\zeta}}>0
$$

The original article was corrected.

The online version of the original article can be found under doi:10.1007/s10290-017-0293-1.

Francesco Di Comite

francesco.di-comite@ec.europa.eu

Antonella Nocco

antonella.nocco@unisalento.it

Gianluca Orefice

gianluca.orefice@cepii.fr

1 Institute for Prospective Technological Studies (IPTS), European Commission, Joint Research Centre, Calle Inca Garcilaso 3, 41092 Seville, Spain

2 Department of Management, Economics, Mathematics and Statistics, University of Salento Ecotekne, Via Monteroni, 73100 Lecce, Italy

3 CEPII, 113 rue de Grenelle, Paris, France 